ORIGINAL ARTICLE

\title{
Effects of a divided high loading dose of caffeine on circulatory variables in preterm infants
}

\author{
C Hoecker, M Nelle, B Beedgen, J Rengelshausen, O Linderkamp
}

Arch Dis Child Fetal Neonatal Ed 2006;91:F61-F64. doi: 10.1136/adc.2005.073866

See end of article for authors' affiliations

Correspondence to: Dr Hoecker, Division of Neonatology, Department of Paediatrics, University of Heidelberg, Im Nevenheimer Feld 150 69120 Heidelberg, Germany; c_hoecker@ hotmail.com

Accepted

17 September 2005

Published online first 4 October 2005

Background: A single high loading dose of $25 \mathrm{mg} / \mathrm{kg}$ caffeine has been shown to be effective for the prevention of apnoea, but may result in considerable reductions in blood flow velocity (BFV) in cerebral and intestinal arteries.

Objective: To assess the effects of two loading doses of $12.5 \mathrm{mg} / \mathrm{kg}$ caffeine given four hours apart on $\mathrm{BFV}$ in cerebral and intestinal arteries, left ventricular output (LVO), and plasma caffeine concentrations in preterm infants.

Design: Sixteen preterm neonates of $<34$ weeks gestation were investigated one hour after the first oral dose and one, two, and 20 hours after the second dose by Doppler sonography.

Results: The mean (SD) plasma caffeine concentrations were 31 (7) and 29 (7) mg/l at two and 20 hours respectively after the second dose. One hour after the first dose, none of the circulatory variables had changed significantly. One hour after the second caffeine dose, mean BFV in the internal carotid artery and anterior cerebral artery showed significant reductions of $17 \%$ and $19 \%(p=0.01$ and $p=0.003$ respectively). BFV in the coeliac artery and superior mesenteric artery, $\mathrm{LVO}, \mathrm{PCO}_{2}$, and respiratory rate had not changed significantly. Total vascular resistance, calculated as the ratio of mean blood pressure to LVO, had increased significantly one and two hours after the second dose $(p=0.049$ and $p=0.023$ respectively).

Conclusion: A divided high loading dose of $25 \mathrm{mg} / \mathrm{kg}$ caffeine given four hours apart had decreased BFV in cerebral arteries after the second dose, whereas BFV in intestinal arteries and LVO were not affected.

$\mathrm{T}$ e methylxanthines aminophylline and caffeine are used to treat and prevent apnoea of prematurity ${ }^{1}$ and to assist weaning of preterm infants from mechanical ventilation. ${ }^{2}$ Scanlon et al have shown that a loading dose of $25 \mathrm{mg} / \mathrm{kg}$ caffeine $(50 \mathrm{mg} / \mathrm{kg}$ caffeine citrate) is more effective in reducing apnoeic episodes within eight hours than a caffeine loading dose of $12.5 \mathrm{mg} / \mathrm{kg}$. Steer et al compared three loading doses of 30,15 , and $3 \mathrm{mg} / \mathrm{kg}$ caffeine followed by half of the loading doses every 24 hours. The two higher dose groups had less apnoea than the lowest dose group after extubation. In a second study, Steer $e t \mathrm{al}^{3}$ compared a very high loading dose of $40 \mathrm{mg} / \mathrm{kg}$ caffeine (followed by $20 \mathrm{mg}$ / kg every 24 hours) with a standard loading dose of $10 \mathrm{mg} / \mathrm{kg}$ (followed by $5 \mathrm{mg} / \mathrm{kg}$ daily). The high dose group showed significant reductions in failure to extubate, duration of ventilation, and apnoea after extubation compared with the low dose group. Thus preterm infants appear to benefit more from a high dosing regimen of caffeine.

However, a high loading dose of $25 \mathrm{mg} / \mathrm{kg}$ caffeine reduced blood flow velocity (BFV) in the cerebral arteries of preterm infants by about $20 \%,{ }^{4}$ whereas a loading dose of $10 \mathrm{mg} / \mathrm{kg}$ caffeine had no effect on BFV in the cerebral arteries at 30120 minutes and at 24 hours. ${ }^{56}$ In adults a caffeine dose of $250 \mathrm{mg}(3-5 \mathrm{mg} / \mathrm{kg}$ ) produced a $20-30 \%$ decrease in whole brain blood flow, ${ }^{7-9}$ and a $13 \%$ decrease in mean $\mathrm{BFV}^{9}$ in cerebral arteries at 15-90 minutes after dietary caffeine consumption. BFV in the superior mesenteric artery (SMA) and coeliac artery (CA) of preterm infants was significantly reduced for one to three hours after a caffeine dose of $25 \mathrm{mg}$ / kg. ${ }^{40}$

There is concern that the reduction in BFV in the cerebral and intestinal arteries after a single loading dose of $25 \mathrm{mg} / \mathrm{kg}$ caffeine $^{4}{ }^{10}$ may increase the risk of cerebral and intestinal ischaemia in preterm infants. A decrease in oxygen supply to vital organs during caffeine treatment may be particularly risky, as oxygen consumption increases by about $20 \%$ during caffeine treatment. ${ }^{11}$

Aranda et $a l^{12}{ }^{13}$ have shown that oral caffeine is almost completely absorbed, with peak plasma concentrations achieved within 30-120 minutes. Four hours after oral caffeine administration, caffeine elimination began. ${ }^{12}$ To avoid high plasma peak concentrations of caffeine, which may be responsible for the reduction in BFV, but to maintain a sufficient plasma concentration, we changed our caffeine dosing regimen from one single high loading dose of $25 \mathrm{mg} /$ $\mathrm{kg}$ caffeine to a divided dose of $2 \times 12.5 \mathrm{mg} / \mathrm{kg}$. The purpose of this investigation was to study the effects of the divided loading dose on circulatory variables.

\section{METHODS}

Sixteen preterm infants with a mean (SD) gestational age of 29 (1) weeks (range 24-33) and a birth weight of 1160 (330) g (690-1720) were studied. Postnatal age at the start of caffeine administration was 4.8 (3.5) days (2-12). Recruited infants were either being weaned from mechanical ventilation or required treatment for apnoea-bradycardia. The study protocol was approved by the ethics committee of the University of Heidelberg Medical Center, and written informed consent was obtained from the parents before entry into the study.

Caffeine was started with a loading dose of $25 \mathrm{mg} / \mathrm{kg}$ ( $50 \mathrm{mg} / \mathrm{kg}$ caffeine citrate) administered in two equal doses of $12.5 \mathrm{mg} / \mathrm{kg}(25 \mathrm{mg} / \mathrm{kg}$ caffeine citrate) four hours apart through a nasogastric tube over 15-20 minutes. The maintenance dose was $5 \mathrm{mg} / \mathrm{kg}$ caffeine daily, beginning 24 hours after the first loading dose. In our neonatal intensive care

Abbreviations: $\mathrm{ACA}$, anterior cerebral artery; $\mathrm{BFV}$, blood flow velocity; CA, coeliac artery; ICA, internal carotid artery; LVO, left ventricular output; SMA, superior mesenteric artery 
unit, caffeine is usually given orally, unless infants do not tolerate feeding. The small number of infants given caffeine intravenously were excluded from the study. No drugs for analgesia or sedation were given during the study period.

Our standard protocol for the use of caffeine was: (a) mechanically ventilated infants with gestational age below 30 weeks at four to six hours before planned extubation; $(b)$ spontaneously breathing preterm infants with four or more apnoea/bradycardia events in two hours. Events were defined as cessation of breathing for more than 15 seconds accompanied by desaturation $\left(\mathrm{SaO}_{2}<85 \%\right)$ and/or bradycardia (heart rate $<80$ beats/min).

Blood pressure was determined using a non-invasive oscillometric method (Dinamap 847; Critikon, Ascot, Surrey, UK). Total vascular resistance was calculated as the ratio of mean blood pressure to left ventricular output (LVO). Levels of transcutaneous $\mathrm{PCO}_{2}$, heart rate, respiratory frequency, and arterial oxygen saturation were monitored continuously (Agilent Technologies, Böblingen, Germany). Two and 20 hours after the second loading dose, venous blood samples were taken, and plasma caffeine concentrations were measured by an enzyme multiplied immunoassay (EMIT, Dade Behring, Schwalbach, Germany).

All Doppler ultrasound studies were performed by the same investigator $(\mathrm{CH})$ immediately before, one hour after the first loading dose, and one, two, and 20 hours after the second loading dose with an Interspec Apogee CX pulsed Doppler ultrasound system (Interspect Inc, Conshohocken, Pennsylvania, USA).

The aortic valve annulus was visualised by $M$ mode echocardiography using the parasternal long axis, and its diameter was measured using the leading edge method in late diastole over five consecutive cycles. From an apical four chamber view, the aortic velocity integrals were recorded with a mechanical $5.0 \mathrm{MHz}$ transducer using the duplex mode at the level of the aortic valve annulus. ${ }^{14}$ Stroke volume was calculated as product of the average time velocity integral and cross sectional area of the aorta. The LVO was calculated as the product of stroke volume and heart rate.

$\mathrm{BFV}$ in the internal carotid artery (ICA) and anterior carotid artery (ACA) was measured using a $5.0 \mathrm{MHz}$ pulsed Doppler transducer from a coronal scan via the anterior fontanel. ${ }^{14}$ The system software was used to calculate maximal systolic, maximal end diastolic, and mean average flow velocity from five consecutive, homogeneous flow waves. Flow velocities in the SMA and CA were measured from a longitudinal abdominal approach using a 5.0 or 7.5 MHZ transducer.

To minimise the effects of feeding on cerebral and intestinal BFV, ${ }^{15} 16$ one meal was omitted if the infants received feeds every two hours, and the volume of the feed was replaced by parenteral fluid. Three infants were excluded because not all the measurements were possible because of either a scalp vein cannula that did not allow the measurements in the ACA or an air filled bowel in front of the SMA.

\section{Statistical analysis}

Results are presented as mean (SD). A $t$ test for paired observations was used to test for changes in the measured variables. All comparisons are with the values before the first loading dose of caffeine.

\section{RESULTS}

The mean (SD) plasma concentrations of caffeine were 31 (7) $\mathrm{mg} / \mathrm{l}$ (range 21-47) two hours after the second loading dose of $12.5 \mathrm{mg} / \mathrm{kg}$ caffeine and 29 (7) mg/l (range 19-45) 20 hours after the second dose. Table 1 shows the effects of the divided caffeine loading dose on circulatory variables for the 24 hours after the first dose. One hour after the first dose of $12.5 \mathrm{mg} / \mathrm{kg}$ caffeine, none of the circulatory variables had changed significantly compared with the values before caffeine. One hour after the second dose, mean BFV in the ICA and ACA had decreased by 17\% and 19\% compared with the basal values. Two hours after the second loading dose, mean BFV in the ACA showed a reduction of $19 \%$. None of the BFV values measured 20 hours after the second dose differed significantly from the values before caffeine.

BFV in the CA and SMA had not changed significantly at any time. Heart rate had increased significantly at the end of the 24 hour observation period ( $p=0.009$ ). LVO, respiratory rate, and $\mathrm{PCO}_{2}$ had not changed significantly after caffeine administration. Diastolic blood pressure had increased one and 20 hours after the second dose $(\mathrm{p}=0.01)$. Total vascular resistance had increased one hour $(\mathrm{p}=0.049)$ and two hours $(\mathrm{p}=0.023)$ after the second caffeine dose.

We observed that, in the six infants breathing spontaneously without continuous positive airway pressure, the frequency of apnoea/bradycardia events decreased from nine to one, seven to four, eight to seven, 15 to eight, 12 to seven, and 11 to five during the first 24 hours after the first caffeine dose compared with the 24 hours preceding the first caffeine dose. Two infants receiving nasal continuous positive airway pressure before caffeine no longer required it after 24 hours. Of the eight mechanically ventilated infants, six could be extubated 3-23 hours after the start of caffeine.

\section{DISCUSSION}

From these data, we reach the following conclusions. (a) One hour after a first dose of $12.5 \mathrm{mg} / \mathrm{kg}$ caffeine $(25 \mathrm{mg} / \mathrm{kg}$ caffeine citrate), BFV in the ICA and ACA tended to decrease, but the differences were not significant (table 1 ). (b) One hour after the second dose of $12.5 \mathrm{mg} / \mathrm{kg}$, mean BFVs in the ICA and ACA decreased by 17-19\% compared with the values before caffeine. (c) The intestinal BFV measured in the CA and SMA and the LVO did not change significantly at any time.

We used Doppler sonography to study the effects of caffeine on circulatory variables. The method is non-invasive and also practicable in extremely preterm infants. However, cerebral and intestinal BFV and LVO are influenced by many factors. Intestinal BFV increases 15-90 minutes after a feed, with a peak at 45 minutes, ${ }^{15}$ whereas cerebral BFV decreases during the first 5-11 minutes after a feed, and reaches prefeeding values after 20 minutes. ${ }^{16}$ To minimise the circulatory effects of feeding, caffeine was given two hours after the last meal. Mechanical ventilation has been shown to decrease BFV in cerebral arteries. ${ }^{17}$ Thus, weaning from ventilation may increase BFV in cerebral arteries. In our study, one mechanically ventilated infant was extubated three hours after the first caffeine dose, and the other seven infants were extubated 7-23 hours after the first dose (3-19 hours after the second dose). Thus, in these seven infants, the BFV measurements one hour after the first dose and one and two hours after the second dose were not influenced by weaning.

Previous studies using caffeine loading doses of $10 \mathrm{mg} / \mathrm{kg}$ showed no significant effect on mean BFV in cerebral vessels at 15-120 minutes and 24 hours after caffeine. ${ }^{56}$ The decreases of $17-19 \%$ in cerebral BFV observed one hour after the second dose in our patients corresponds to the reductions in BFV found one and two hours after one high loading dose of $25 \mathrm{mg} / \mathrm{kg}^{4}{ }^{4}$ Intravenous aminophylline doses of $5-10 \mathrm{mg} /$ $\mathrm{kg}^{18-21}$ reduced cerebral blood flow, ${ }^{18}{ }^{19} \mathrm{BFV},{ }^{20}{ }^{21}$ and blood volume in preterm infants. ${ }^{22}$ Intravenous doxapram, ${ }^{23}$ another drug used to prevent apnoea of prematurity, was also associated with a decreased cerebral BFV in preterm infants.

The decrease in BFV in cerebral arteries after the second caffeine dose was probably attributable to vasoconstriction, 


\begin{tabular}{|c|c|c|c|c|c|}
\hline Variable & Before caffeine & $\begin{array}{l}1 \text { hour after } \\
\text { LD } 1\end{array}$ & $\begin{array}{l}1 \text { hour after } \\
\text { LD } 2\end{array}$ & $\begin{array}{l}2 \text { hours after } \\
\text { LD } 2\end{array}$ & $\begin{array}{l}20 \text { hours after } \\
\text { LD } 2\end{array}$ \\
\hline \multicolumn{6}{|l|}{ BFV in ICA } \\
\hline Systolic (m/s) & $0.38(0.10)$ & $0.33(0.07)$ & $\begin{array}{l}0.32(0.08) \\
p=0.0063\end{array}$ & $0.33(0.08)$ & $0.33(0.09)$ \\
\hline End diastolic (m/s) & $0.09(0.03)$ & $0.08(0.03)$ & $0.08(0.02)$ & $0.08(0.02)$ & $0.09(0.02)$ \\
\hline Mean $(\mathrm{m} / \mathrm{s})$ & $0.18(0.05)$ & $0.16(0.03)$ & $\begin{array}{l}0.15(0.03) \\
p=0.0103\end{array}$ & $0.16(0.04)$ & $0.16(0.03)$ \\
\hline \multicolumn{6}{|l|}{$\mathrm{BFV}$ in $\mathrm{ACA}$} \\
\hline Systolic (m/s) & $0.30(0.07)$ & $0.28(0.08)$ & $\begin{array}{l}0.26(0.07) \\
p=0.0065\end{array}$ & $0.27(0.07)$ & $0.31(0.08)$ \\
\hline End diastolic (m/s) & $0.09(0.02)$ & $0.07(0.03)$ & $0.08(0.02)$ & $0.08(0.02)$ & $0.09(0.02)$ \\
\hline Mean $(\mathrm{m} / \mathrm{s})$ & $0.16(0.04)$ & $0.14(0.04)$ & $\begin{array}{l}0.13(0.03) \\
p=0.0027\end{array}$ & $\begin{array}{l}0.13(0.03) \\
p=0.0083\end{array}$ & $0.16(0.04)$ \\
\hline \multicolumn{6}{|l|}{ BFV in CA } \\
\hline Systolic (m/s) & $0.62(0.18)$ & $0.57(0.18)$ & $0.56(0.14)$ & $0.56(0.18)$ & $0.56(0.17)$ \\
\hline End diastolic (m/s) & $0.2(0.08)$ & $0.19(0.09)$ & $0.19(0.07)$ & $0.18(0.07)$ & $0.19(0.08)$ \\
\hline Mean $(\mathrm{m} / \mathrm{s})$ & $0.32(0.13)$ & $0.3(0.12)$ & $0.3(0.08)$ & $0.29(0.11)$ & $0.29(0.11)$ \\
\hline \multicolumn{6}{|l|}{ BFV in SMA } \\
\hline Systolic $(\mathrm{m} / \mathrm{s})$ & $0.54(0.19)$ & $0.48(0.15)$ & $0.54(0.17)$ & $0.48(0.14)$ & $0.51(0.12)$ \\
\hline End diastolic (m/s) & $0.14(0.07)$ & $0.13(0.04)$ & $0.13(0.04)$ & $0.12(0.04)$ & $0.14(0.06)$ \\
\hline Mean $(\mathrm{m} / \mathrm{s})$ & $0.24(0.09)$ & $0.21(0.07)$ & $0.24(0.07)$ & $0.21(0.07)$ & $0.24(0.06)$ \\
\hline $\operatorname{LVO}(\mathrm{ml} / \mathrm{kg} / \mathrm{min})$ & $238(55)$ & $250(66)$ & $221(55)$ & $217(60)$ & $232(53)$ \\
\hline HR (beats/min) & 149 (11) & 147 (13) & 153 (17) & $151(15)$ & $\begin{array}{l}158(14) \\
p=0.0091\end{array}$ \\
\hline \multicolumn{6}{|l|}{ Blood pressure } \\
\hline Systolic (mm Hg) & $56(9)$ & $55(9)$ & $57(9)$ & $59(10)$ & $57(8)$ \\
\hline Diastolic (mm Hg) & $35(5)$ & $34(8)$ & $\begin{array}{l}39(7) \\
p=0.0102\end{array}$ & $38(8)$ & $\begin{array}{l}39(7) \\
p=0.0135\end{array}$ \\
\hline \multirow[b]{2}{*}{ TVR (MBP/LVO) } & $42(6)$ & $40(7)$ & $45(7)$ & $45(8)$ & $45(7)$ \\
\hline & $0.18(0.04)$ & $0.17(0.05)$ & $\begin{array}{l}0.21(0.05) \\
p=0.0494\end{array}$ & $\begin{array}{l}0.22(0.05) \\
p=0.0227\end{array}$ & $0.20(0.05)$ \\
\hline Respiratory rate & $53(16)$ & $54(18)$ & $58(13)$ & $56(15)$ & $56(13)$ \\
\hline $\mathrm{PCO}_{2}$ & $48(8)$ & $46(6)$ & $46(6)$ & $45(7)$ & $46(9)$ \\
\hline \multicolumn{6}{|c|}{$\begin{array}{l}\text { Values are mean (SD). A } t \text { test for paired observations was used to test for changes in the measured variables. All } \\
\text { comparisons are with the values before the first loading dose of caffeine. Only p values }<0.05 \text { are shown. } \\
\text { ACA, anterior cerebral artery; BFV, blood flow velocity; CA, coeliac artery; HR, heart rate; ICA, internal carotid } \\
\text { artery; LVO, left ventricular output; MBP, mean blood pressure; SMA, superior mesenteric artery; TVR, total } \\
\text { vascular resistance. }\end{array}$} \\
\hline
\end{tabular}

as the diastolic blood pressure tended to increase (table 1). At high concentrations, caffeine and theophylline are potent inhibitors of the vasodilator adenosine. This may result in vasoconstriction of cerebral vessels or attenuation of adenosine induced vasodilation-for example, during hypoxaemia. $^{24}$

The divided loading dose did not affect intestinal BFV, whereas a single high dose of $25 \mathrm{mg} / \mathrm{kg}$ caffeine decreased $\mathrm{BFV}$ in the CA and SMA by $14-30 \%{ }^{4}{ }^{10}$ It is unclear if a decrease in BFV in intestinal arteries during treatment with methylxanthines increases the risk of necrotising enterocolitis. Uncontrolled, retrospective studies showed that oral theophylline increased the risk of necrotising enterocolitis, whereas intravenous theophylline did not. ${ }^{25}{ }^{26}$ Animal experiments showed that aminophylline increases the risk of ischaemic bowel damage after a short ischaemic insult. ${ }^{27}$ Steer $e a^{2}{ }^{3}$ found no increase in the incidence of necrotising enterocolitis after high intravenous loading and maintenance doses of caffeine. In our previous study ${ }^{4}$ and the present one, none of the infants included developed necrotising

\section{What is already known on this topic}

- High loading doses of caffeine are more effective for the treatment and prevention of apnoea

- However, after a single high loading dose of $25 \mathrm{mg} /$ $\mathrm{kg}$ caffeine, decreases in cerebral and intestinal blood flow velocity have been found enterocolitis. Thus high dose caffeine appears to be safe if used in infants without hypoxaemia, but may worsen ischaemic bowel disease.

Walther $e t a^{28}$ found a rise in LVO by about $15 \%$ and an increase in mean blood pressure by $10 \% 24$ hours after a caffeine loading dose of $10 \mathrm{mg} / \mathrm{kg}$. We found a similar increase in the diastolic blood pressure one and 20 hours after the second loading dose (table 1). Total vascular resistance tended to decrease in the infants receiving a loading dose of $10 \mathrm{mg} / \mathrm{kg}$ caffeine, ${ }^{28}$ whereas in our patients total vascular resistance had increased one and two hours after the second dose. This suggests that a standard caffeine dose of $10 \mathrm{mg} / \mathrm{kg}$ results in overall systemic vasodilation (except in the brain ${ }^{5}{ }^{6}$ ), whereas a high dose of $25 \mathrm{mg} / \mathrm{kg}$ results in overall vasoconstriction (including the brain).

There is concern that methylxanthines may have long term adverse effects on the developing nervous system of premature infants. ${ }^{29}$ Animal experiments suggest that

\section{What this study adds}

- Oral administration of a divided loading dose of $2 \times$ $12.5 \mathrm{mg} / \mathrm{kg}$ caffeine given four hours apart resulted in reductions in cerebral blood flow velocity whereas intestinal blood flow velocity did not change significantly

- The regimen of a divided high loading dose of caffeine seems to be safer than a single high loading dose 
adenosine receptor blockade in early life by methylxanthines may alter neuronal differentiation, migration, and synaptogenesis. ${ }^{30}$ Neonatal exposure of animals to caffeine disrupted $\mathrm{A}_{1}$ adenosine receptor ontogeny. ${ }^{31}$ Moreover, acute adenosine receptor blockade with aminophylline increased cerebral metabolic rate and increased the risk of anoxic brain damage and death in young mice. ${ }^{32}$

Steer $\mathrm{et} \mathrm{al}^{3}$ studied neurological outcomes at 12 months of corrected age. They found similar Griffiths developmental scales in the high and low dose group, but a higher incidence of major disabilities in the low dose compared with the high dose group ( $18 \% \vee 7.5 \% ; \mathrm{p}=0.05)$. In contrast, Davis et al ${ }^{33}$ reported an appreciably higher incidence of cerebral palsy in 14 year old children with birth weight below $1501 \mathrm{~g}$ who were treated with theophylline in the newborn period than prematurely born infants without methylxanthine treatment $(13.0 \% v 1.6 \%)$. On the other hand, the theophylline treated group had a better sensorineural outcome at 14 years than the controls.

We summarise that gastric application of a high caffeine loading dose of $25 \mathrm{mg} / \mathrm{kg}$ in two doses of $12.5 \mathrm{mg} / \mathrm{kg}$ given four hours apart decreases the BFV in cerebral arteries by a similar extent to a single loading dose of $25 \mathrm{mg} / \mathrm{kg}$. ${ }^{4}$ However, $\mathrm{BFV}$ in intestinal arteries was less affected by a divided loading dose than by a single caffeine dose of $25 \mathrm{mg} / \mathrm{kg} .{ }^{4}{ }^{10} \mathrm{~A}$ reduction in cerebral BVF of $20 \%$ for one and two hours after caffeine administration is probably not meaningful for infants with adequate cerebral oxygen supply. However, it may compromise an infant's ability to respond to hypoxaemia by vasodilation. Moreover, accumulation of caffeine from high maintenance doses of $15 \mathrm{mg} / \mathrm{kg}$ results in high plasma concentrations of up to $90 \mathrm{mg} / \mathrm{dl} .{ }^{34}$ Further studies should investigate circulatory variables serially in preterm infants receiving such high doses.

\section{Authors' affiliations}

C Hoecker, B Beedgen, O Linderkamp, Division of Neonatology, Department of Paediatrics, University of Heidelberg, Heidelberg, Germany

M Nelle, Division of Neonatology, Department of Paediatrics, University of Berne, Berne, Switzerland

J Rengelshausen, Department of Internal Medicine VI, Clinical Pharmacology and Pharmacoepidemiology, University of Heidelberg

Competing interests: none declared

\section{REFERENCES}

1 Scanlon JEM, Chin KC, Morgan MEl, et al. Caffeine or theophylline for neonatal apnoea? Arch Dis Child 1992;67:425-8.

2 Steer $\mathbf{P}$, Flenady V, Shearman A, et al. Periextubation caffeine in preterm neonates: a randomized dose response trial. J Paediatr Child Health 2003;39:511-15

3 Steer $\mathbf{P}$, Flenady $V$, Shearman A, et al. High dose caffeine citrate for extubation of preterm infants: a randomized controlled trial. Arch Dis Child Fetal Neonatal Ed 2004:89:F499-503.

4 Hoecker C, Nelle M, Poeschl J, et al. Caffeine impairs cerebral and intestinal blood flow velocity in preterm infants. Pediatrics 2002;109:784-8.

5 Saliba E, Autret E, Gold F, et al. Effect of caffeine on cerebral blood flow velocity in preterm infants. Biol Neonate 1989;56:198-203.
6 Van Bel F, van de Bor M, Stijnen T, et al. Does caffeine affect cerebral blood flow in the preterm infant? Acta Paediatr Scand 1989;78:205-9.

7 Cameron OG, Modell JG, Hariharan M. Caffeine and human cerebral blood flow: a positron emission tomography study. Life Sci 1990;47:1141-6.

8 Field AS, Laurenti PJ, Yen YF, et al. Dietary caffeine consumption and withdrawal: confounding variables in quantitative cerebral perfusion studies? Radiology 2003;227:129-35.

9 Lunt MJ, Ragab S, Birch AA, et al. Comparison of caffeine-induced changes in cerebral blood flow and middle cerebral artery blood velocity shows that caffeine reduces middle cerebral artery diameter. Physiol Meas 2004;25:467-74.

10 Lane AJP, Coombs RC, Evans DH, et al. Effect of caffeine on the neonatal splanchnic blood flow. Arch Dis Child Fetal Neonatal Ed 1999;80:F128-9.

11 Baver J, Maier K, Linderkamp O, et al. Effect of caffeine on oxygen consumption and metabolic rate in very low birth weight infants with idiopathic apnea. Pediatrics 2001;107:660-3.

12 Aranda,JV, Cook CE, Gorman W, et al. Pharmacokinetic profile of caffeine in the premature newborn infant with apnea. J Pediatr, 1979;94, 663-8.

13 Aranda JV, Gorman W, Bergsteinsson H, et al. Efficacy of caffeine in treatment of apnea in the low-birth-weight infant. J Pediatr, 1979;90, 467-72.

14 Nelle M, Hoecker C, Zilow EP, et al. Effects of red cell transfusion on cardiac output and blood flow velocities in cerebral and gastrointestinal arteries in premature infants. Arch Dis Child Fetal Neonatal Ed, 1994;71, F45-8.

15 Leidig E. Doppler analysis of superior mesenteric artery blood flow in preterm infants. Arch Dis Child 1989;64:476-80.

16 Nelle M, Hoecker C, Linderkamp O. Effects of bolus tube feeding on cerebral blood flow velocity in neonates. Arch Dis Child Fetal Neonatal Ed 1997;76:F54-6.

17 Cowan F, Thoresen M. The effects of intermittent positive pressure ventilation on cerebral arterial and venous blood velocities in the newborn infant. Acta Paediatr Scand 1987;76:239-47.

18 Pryds O, Schneider S. Aminophylline reduces cerebral blood flow in stable, preterm infants without affecting the visual evoked potential. Eur J Pediatr, 1991;150:366-9.

19 McDonnell M, Ives NK, Hope PL. Intravenous aminophylline and cerebral blood flow in preterm infants. Arch Dis Child, 1992;67, 416-18.

20 Rosenkrantz TS, William $\mathrm{OH}$. Aminophylline reduces cerebral blood flow velocity in low-birth-weight infants. Am J Dis Child 1984;138:489-91.

21 Chang J, Gray PH. Aminophylline therapy and cerebral blood flow velocity in preterm infants. J Paediatr Child Health 1994;30:123-5.

22 Bucher HU, Wolf $M$, Keel $M$, et al. Effect of aminophylline on cerebral haemodynamics and oxidative metabolism in premature infants. Eur J Pediatr 1994;153:123-8.

23 Roll C, Horsch S. Effect of doxapram on cerebral blood flow velocity in preterm infants. Neuropediatrics 2004;35:126-9.

24 Smits $\mathbf{P}$, Lenders JW, Thien T. Caffeine and theophylline attenuate adenosineinduced vasodilation in humans. Clin Pharmacol Ther 1990:48:410-18.

25 Robinson MJ, Clayden GS, Smith MF. Xanthines and necrotising enterocolitis. Arch Dis Child 1980;55:494-5.

26 Jones RAK. Xanthines and necrotising enterocolitis. Arch Dis Child 1981;5:238.

27 Grosfeld JL, Dalsing MC, Hull M, et al. Neonatal apnea, xanthines, and necrotizing enterocolitis. J Pediatr Surg 1983;19:80-4

28 Walther FJ, Erickson R, Sims ME. Cardiovascular effects of caffeine therapy in preterm infants. Am J Dis Child 1990;144:1164-6.

29 Millar D, Schmidt B. Controversies surrounding xanthine therapy. Semin Neonatol 2004;9:239-244.

30 Weaver DR. $A_{1}$-adenosine receptor gene expression in fetal rat brain. Brain Res Dev Brain Res 1996;94:205-23.

31 Etzel BA, Guillet R. Effects of neonatal exposure to caffeine on adenosine $A_{1}$ receptor ontogeny using autoradiography. Brain Res Dev Brain Res 1996;82:223-30

32 Thurston JH, Hauhard RE, Dirgo JA. Aminophylline increases cerebral metabolic rate and decreases anoxic survival in young mice. Science 1978;201:649-51.

33 Davis PG, Doyle LW, Rickards AL, et al. Methylxanthines and sensorineural outcome at 14 years in children $<1501 \mathrm{~g}$ birthweight. J Paediatr Child Health 2000;36:47-50.

34 Lee TC, Charles B, Steer P, et al. Population pharmacokinetics of intravenous caffeine in neonates with apnea of prematurity. Clin Pharmacol Ther 1997;61:628-40 